\title{
An innovative financing model for the progesterone contraceptive vaginal ring through voucher programs
}

\author{
Ishita Chattopadhyay \\ Population Council \\ John Townsend \\ Population Council \\ Saumya RamaRao \\ Population Council
}

Follow this and additional works at: https://knowledgecommons.popcouncil.org/departments_sbsr-rh

Part of the Demography, Population, and Ecology Commons, Family, Life Course, and Society Commons, International Public Health Commons, and the Women's Health Commons How does access to this work benefit you? Let us know!

\section{Recommended Citation}

Chattopadhyay, Ishita, John Townsend, and Saumya RamaRao. 2015. "An innovative financing model for the progesterone contraceptive vaginal ring through voucher programs." Washington, DC: Population Council. 


\section{AN INNOVATIVE FINANCING MODEL FOR THE PROGESTERONE CONTRACEPTIVE VAGINAL RING THROUGH VOUCHER PROGRAMS}

Ishita Chattopadhyay John W. Townsend Saumya RamaRao 


\section{POPULATION}

COUNCIL

Ideas. Evidence. Impact.

The Population Council confronts critical health and development issuesfrom stopping the spread of HIV to improving reproductive health and ensuring that young people lead full and productive lives. Through biomedical, social science, and public health research in 50 countries, we work with our partners to deliver solutions that lead to more effective policies, programs, and technologies that improve lives around the world. Established in 1952 and headquartered in New York, the Council is a nongovernmental, nonprofit organization governed by an international board of trustees.

Population Council

4301 Connecticut Avenue, NW, Suite 280

Washington, DC 20008

Tel: +12022379400

Fax: +1202 2378410

popcouncil.org

Suggested citation: Chattopadhyay, I., J.W. Townsend and S. RamaRao. 2015. "An innovative financing model for the Progesterone Contraceptive Vaginal Ring through voucher programs." Washington, DC: Population Council.

\section{AN INNOVATIVE FINANCING MODEL FOR THE PROGESTERONE CONTRACEPTIVE VAGINAL RING THROUGH VOUCHER PROGRAMS}

This technical report is part of a series of reports investigating the introduction of the PCVR in the context of quality, choice, equity and improved access. Each report provides information about the product and its benefits in addressing the gap in postpartum family planning (PPFP); offers a pathway for marketing and assumes that products will be available from manufacturers and distributors to respond to women's needs in diverse markets. Other reports in this series include:

- Utilizing social marketing and social franchising models to expand access to the Progresterone Contraceptive Vaginal Ring

- Offering Progesterone Contraceptive Vaginal Ring for postpartum women through integrated family planning and immunization services

(C) 2015 The Population Council, Inc. 


\section{Table of Contents}

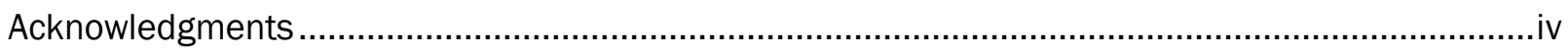

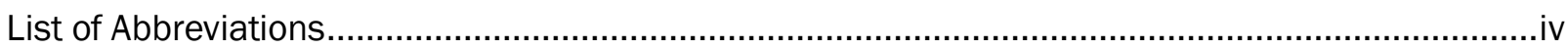

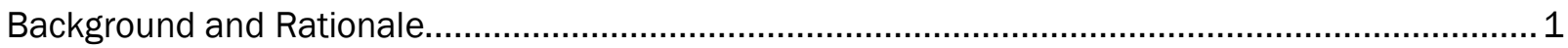

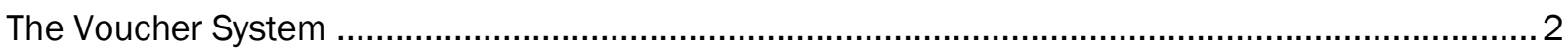

The PCVR Voucher-Based Care Model (PCVR-VBC) ................................................................... 4

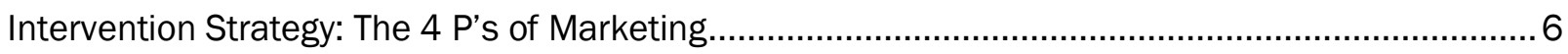

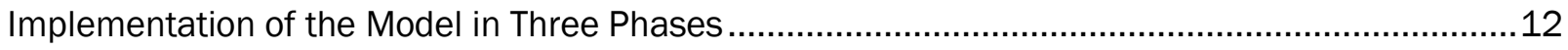

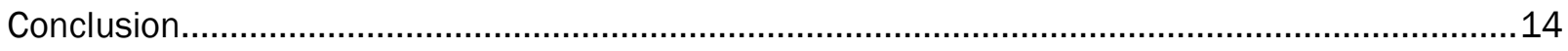

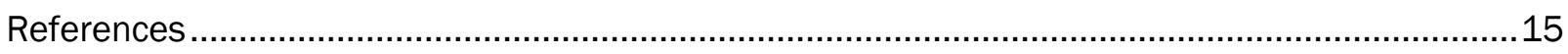

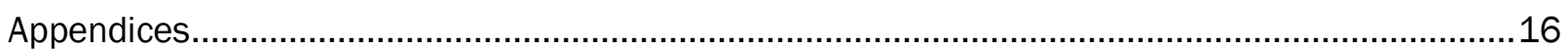




\section{Acknowledgments}

This report was developed under the larger project 'Delivering Contraceptive Vaginal Rings' funded by USAID under the Annual Program Statement number SOL-OAA-13-000024, Agreement number AID-OAAA-13-00075. The project aims to strategically introduce the Progesterone Contraceptive Vaginal Ring (PCVR) as a new contraceptive option for postpartum family planning.

We would like to thank Ben Bellows from Population Council for his support and expert advice on how to design and manage Reproductive Health Voucher Systems in low-income countries. This has helped us shape the PCVR Voucher Based Care Model.

The opinions expressed in this report are those of the authors and do not reflect the views of its funding or implementing agencies.

\section{List of Abbreviations}

\begin{tabular}{|c|c|}
\hline BPL & Below Poverty Line \\
\hline CHW & Community Health Worker \\
\hline CVD & Community Voucher Distributor \\
\hline DCVR & Delivering Contraceptive Vaginal Rings \\
\hline DHS & Demographic and Health Survey \\
\hline $\mathrm{DRH}$ & Department of Reproductive Health \\
\hline FP & Family Planning \\
\hline GoK & Government of Kenya \\
\hline HIP & High Impact Practice \\
\hline IEC & Information, Education and Communication \\
\hline IUCD & Intrauterine Contraceptive Device \\
\hline LAM & Lactational Amenorrhea Method \\
\hline LARC & Long-acting Reversible Contraceptive \\
\hline MDP & Market Development Plan \\
\hline MDG & Millennium Development Goal \\
\hline $\mathrm{MoH}$ & Ministry of Health \\
\hline NCAPD & National Coordinating Agency for Population and Development \\
\hline NGO & Non-governmental Organization \\
\hline OBA & Output Based Aid \\
\hline PCVR & Progesterone Contraceptive Vaginal Ring \\
\hline PoP & Progesterone only Pill \\
\hline PPFP & Postpartum Family Planning \\
\hline PSA & Public Service Announcements \\
\hline $\mathrm{RH}$ & Reproductive Health \\
\hline SM & Safe Motherhood \\
\hline TAC & Technical Advisory Committee \\
\hline USAID & United States Agency for International Development \\
\hline VBC & Voucher Based Care \\
\hline VMA & Voucher Management Agency \\
\hline VSP & Voucher Service Provider \\
\hline WHO & World Health Organization \\
\hline WTP & Willingness to Pay \\
\hline
\end{tabular}




\section{Background and Rationale}

With the Millennium Development Goals (MDG) ending in 2015, the MDG 5 goal of 'Improving Maternal Health' through better access to reproductive health continues to lag in addressing the family planning needs among low-income postpartum women. According to Demographic Health Surveys (DHS) conducted in 27 countries, more than $65 \%$ of women who are 0-12 months postpartum and want to delay or avoid pregnancy are not using contraception (Ross and Winfrey, 2001). Failure to meet women's contraceptive needs during this critical period has consequences for maternal and infant health (WHO, 2014).

The Progesterone Contraceptive Vaginal Ring (PCVR) is an effective, user-initated contraceptive option which helps meet the need for postpartum family planning (PPFP). It is exclusively designed for postpartum breastfeeding women who want to space or delay pregnancies in the first year following childbirth. The PCVR can be used by lactating mothers as early as 6 weeks postpartum and can be easily inserted and removed from the vagina without the need for clinical help or supervision. Each PCVR diffuses 10mg of natural progesterone per day (which suppresses ovulation). Women can use a ring continuously for up to 3 months and up to 4 rings in the first year following childbirth.

In many low-income countries, low contraceptive prevalence is the result of both demand and supply factors (Obare et al, 2012). On the demand side, the direct cost of reproductive health services is often prohibitive to women from low-income communities. According to a study conducted by Abuya et al (2013), women often perceive maternal and family planning (FP) services to be costly and tend to avoid or delay getting such services. To reduce these financial barriers, donors and governments have invested in innovative models where financial payments and incentive are linked to the output and quality of services rendered. The use of vouchers has been recognized as a promising high-impact strategy and has considerable appeal in the targeted low-income markets (Grainger et al, 2014).

This technical report introduces the theoretical framework for the demand generation and supply chain mechanisms for an effective reproductive health voucher system. The following sections describe the key roles and functions of an effective voucher system.

A methodology for implementation of the PCVR voucher system, also referred to as the PCVR Voucher Based Care (VBC) program, has been designed to introduce PCVR in the context of choice, equity in price and range of outlets; ensuring quality of care and consistent availability of services. The model provides a framework and guidelines on how PCVR can be included in existing voucher programs. A proposed structure to introduce and integrate PCVR into the voucher system has been outlined and described in 3 phases: the design phase, the start-up phase and the scale-up phase.

This technical report may be used by family planning and reproductive health service implementers and program managers who wish to implement the PCVR-VBC program. The report provides detailed information about the various aspects of planning required to integrate PCVR at a country level. The implementing partners or managers have been referred to as the "project" throughout the document. 


\section{The Voucher System}

The voucher system is an innovative financing strategy that integrates supply and demand incentives to reduce financial barriers to maternal and reproductive health services for low-income and disadvantaged populations (Abuya et al, 2012). This system targets demand subsidies to low-income clients, who in the absence of the voucher would have a low probability of affording or seeking services. Clients can exchange a voucher to voluntarily access FP services and products at free or subsidized rates (Bellows et al, 2011). The clients are primarily from low-income or disadvantaged households. Depending on the program, there are minimum eligibility criteria, often through a poverty grading tool. In many programs, vouchers are sold to low-income clients at a minimal price in order to generate revenue and familiarize clients with the concept of pre-payment for needed health services (Bellows $\mathrm{N}$, 2012). A minimal fee for service also adds value to the products and services that the clients obtain. Clients also associate any cost or purchase with a higher quality of care, as opposed to receiving free services. The other reasons for selling vouchers are to (1) subsidize some of the administrative and management costs in the health facilities and (2) enable clients to participate in the running of the services as a strategy for long-term sustainability of the services provided.

The voucher method also works as an incentive to providers that helps bolster the supply chain mechanisms. Providers are able to increase their clientele, with a higher likelihood of follow-up by older clients. The revenue generated from clients helps providers to improve their infrastructure, and the accreditation process can foster greater competition, which in turn improves efficiency and boosts the quality of care (Bellows, 2012; Abuya et al, 2012). Research by Bellows et al (2013) suggests that the voucher programs can work well with both public and private facilities.

Most reproductive health voucher programs involve six primary actors: (1) funding organizations; (2) the voucher management agency (VMA) that contracts providers, checks quality of services, and identifies beneficiaries; (3) the governing bodies who regulate the health market; (4) the service providers; (5) the voucher distributors; and (6) the beneficiaries (Grainger et al, 2014; Bellows, 2012; Bellows et al, 2013).

The following are roles and functions of the 6 primary actors:

- The key function of the financing organization is to provide funding for start-up and scale-up of a voucher program. While there is an initial administrative setup cost, most of the funding is channeled towards reimbursement of providers for the supply of products and services, followed by the marketing and distribution costs to foster demand generation.

- The Voucher Management Agency (VMA) plays a key role in administering voucher programs through accrediting and contracting providers, ensuring quality, provider training for communitybased distribution, marketing and raising awareness of the voucher system among the target population, targeting a specific segment of the population where applicable and processing provider claims and conducting fraud control (Bellows N, 2012).

- The government as steward oversees the market in which the program operates. Governing bodies such as a steering committee provide regular recommendations on the design, cost, organizational structure of the program; integration of the voucher management information system with health sector financial and information systems; capacity development and management of quality control (Abuya et al, 2012). They may also contract independent accreditation and claims processing agencies to manage quality of services or timely reimbursements to providers. 
- The Voucher Service Providers (VSPs) can include clinic-based physicians as well as mid-level health workers such as nurses, midwives and community health workers who provide FP/RH products and services. It will be necessary for the VSPs to undergo mandatory training before being contracted into the program in order to ensure consistent quality of care. The VSPs will be accredited based on pre-defined quality parameters (USAID, 2009). The VSPs need to meet minimum quality standards and participate in training in order to be accredited as a voucher facility, thereby improving the quality of services in many facilities. Once contracted, VSPs can receive and redeem vouchers. VSPs may be contracted from both the public and private sector, depending on national health-sector policies.

- Community Voucher Distributors (CVD) play a key role in identifying, educating and marketing RH vouchers to eligible low-income beneficiaries, often using a poverty grading tool. The CVDs can include individual contractors, NGOs, social marketing organizations and faith-based organizations (USAID, 2009). The CVDs raise awareness through community meetings and door-to-door communication (Arur et al, 2009; Bellows et al, 2013). CVDs are recruited by the VMA and undergo training and regular monitoring to control for fraud and program adherence.

- Beneficiaries are an important actor in the program, and care is taken to ensure the intended disadvantaged population is reached appropriately.

In the context of PCVR, the voucher system presents an opportunity to reach postpartum women in poor urban and rural areas and where there is limited access to FP services. The PCVR voucher system, also known as "Voucher Based Care" (VBC), describes the process through which the vouchers for PCVR can be obtained at subsidized prices. The model also enumerates the key roles and functions of the 6 actors to develop and maintain an effective voucher system.

\section{THE GOAL OF THE PCVR-VOUCHER BASED CARE MODEL}

The goal of the PCVR-Voucher Based Care (PCVR-VBC) intervention is to reduce cost of PCVR to clients through subsidies and thereby expand access to PCVR in targeted low-income communities. The VBC program will aim to introduce PCVR by partnering with the public and private sector distribution networks that are already providing voucher subsidies for $\mathrm{FP} / \mathrm{RH}$ and $\mathrm{MCH}$ services.

\section{Key Objectives}

- To increase access to the PCVR in low-income communities

- To meet the demand for postpartum contraception among target beneficiaries in low-income communities

- To reduce financial barriers among economically disadvantaged women to new contraceptives such as the PCVR

- To manage and increase the supply of PCVR to public and private providers serving low-income communities 


\section{The PCVR Voucher Based Care Model (PCVR-VBC)}

The PCVR voucher protocol has been designed with the goal of increasing accessibility, affordability, availability and quality related to care of PCVR in low-income communities. The key market segment for the PCVR-VBC program will include postpartum women in low-income communities, in peri-urban, slum and rural areas. The target populations are breastfeeding postpartum women, from 0-1 year following childbirth, (usually) from the bottom two wealth quintiles (Van de Poe et al, 2014).

The strategy for this intervention is to identify areas of collaboration with current voucher programs that provide maternal health and PPFP services. Funding resources may need be identified both locally and internationally to provide subsidies for PCVR. Also efforts will need to be made to negotiate strategies for scale-up in target countries to expand access to peri-urban, rural/ below poverty line (BPL) areas where there is a significantly higher unmet need for postpartum family planning.

The PCVR Voucher Based Care (PCVR-VBC) model as represented in Figure 1 describes of a demand and supply mechanism for the distribution of the vaginal rings and other essential health products and services. The voucher management agency (VMA) typically receives funding and program oversight from the donors and governing bodies to implement the program. The VMA will then provide PCVR vouchers to community-based distributors. The next step is to approach the target population through community sensitization visits or other marketing events. Once the clients have a good understanding of the benefits of the vaginal ring and the service offered, they may receive the voucher from the distributor at a highly subsidized rate and may redeem the voucher at accredited health centers for the service specified. Once the provider has completed the required service, they will need to submit a claim to the management agency for reimbursement.

FIGURE 1: PCVR VOUCHER BASED CARE MODEL

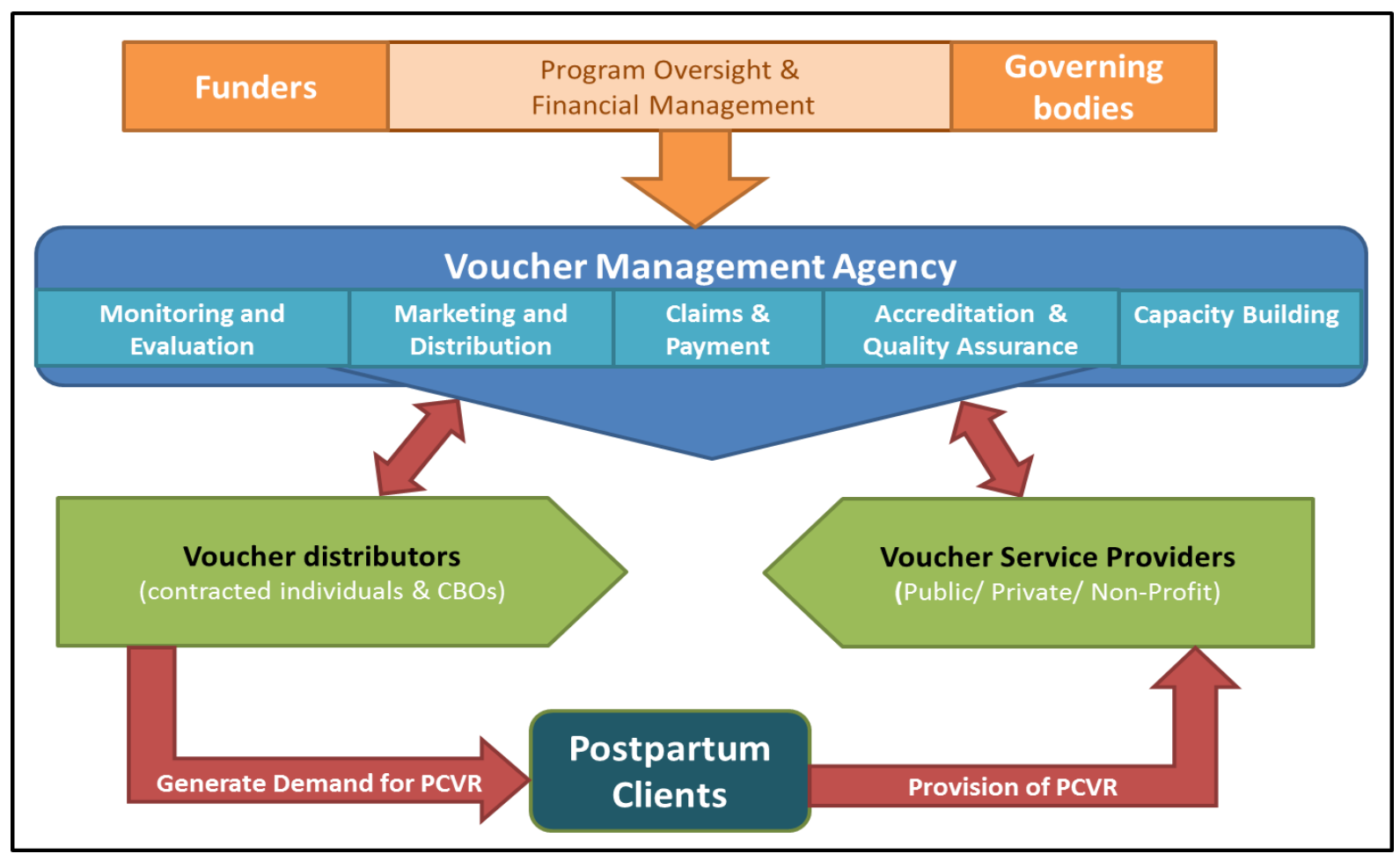


Table 1 highlights the key stakeholders (providers) and main functions of the PCVR-VBC program. The four main categories that describe the key roles and functions of the program include: (1) Program Stewardship, (2) Voucher Management Agency, (3) Service Delivery (supply), and (4) Demand Generation.

\section{TABLE 1: KEY FUNCTIONS AND STAKEHOLDERS OF THE PCVR VOUCHER BASED CARE PROGRAM}

\begin{tabular}{|c|c|c|}
\hline Category & Key Functions & Stakeholders \\
\hline $\begin{array}{l}\text { Program } \\
\text { Stewardship }\end{array}$ & $\begin{array}{l}\text { - Defining PCVR voucher program } \\
\text { - Providing technical support and overseeing the voucher } \\
\text { program } \\
\text { - Financing and planning for long-term sustainability }\end{array}$ & $\begin{array}{l}\text { Donors, } \mathrm{MoH}, \\
\text { National FP/RH } \\
\text { organizations, } \\
\text { advocacy groups and } \\
\text { industry partners }\end{array}$ \\
\hline $\begin{array}{l}\text { Voucher } \\
\text { Management } \\
\text { Agency }\end{array}$ & $\begin{array}{l}\text { - Processing voucher claims for PCVR } \\
\text { - Monitoring and controlling fraud and eligibility criteria of } \\
\text { clients } \\
\text { - Managing quality assurance of VSPs } \\
\text { - Recruiting distributors } \\
\text { - Providing vouchers and marketing materials to distributors }\end{array}$ & $\begin{array}{l}\text { Private organization } \\
\text { contracted by the } \\
\text { Ministry of Health } \\
\text { and donor }\end{array}$ \\
\hline $\begin{array}{l}\text { Service Delivery } \\
\text { (supply) }\end{array}$ & $\begin{array}{l}\text { - Identifying, accrediting and contracting providers and } \\
\text { distributors } \\
\text { - Ensuring availability and adequate supplies of PCVR to VMA, } \\
\text { VSPs and CVDs. } \\
\text { - Regular monitoring to ensure quality of care } \\
\text { - Training of VMA, VSPs on PCVR service delivery }\end{array}$ & $\begin{array}{l}\text { Public/ Private/ Non- } \\
\text { profit providers such } \\
\text { as physicians, } \\
\text { nurses, midwives } \\
\text { and community } \\
\text { health workers }\end{array}$ \\
\hline $\begin{array}{l}\text { Demand } \\
\text { Generation }\end{array}$ & $\begin{array}{l}\text { - Training CVDs on PCVR features and frequently asked } \\
\text { questions } \\
\text { - Identifying target clients through home-visit and community } \\
\text { mobilization } \\
\text { - Distributing promotional materials } \\
\text { - Marketing and selling vouchers } \\
\text { - Referral to healthcare facilities as appropriate }\end{array}$ & $\begin{array}{l}\text { Individually } \\
\text { contracted } \\
\text { distributors,commun } \\
\text { ity based } \\
\text { organizations, media } \\
\text { agencies }\end{array}$ \\
\hline
\end{tabular}

The implementation activities of the key components of the PCVR-VBC model are described in the following section. The activities utilize the four fundamental P's of marketing, also referred to as the "Marketing Mix," which are: Providers, Promotion, Place and Price (Chattopadhyay et al, unpublished). 


\section{Intervention Strategy: The 4 P's of Marketing}

The following section discusses the "marketing mix" for integrating PCVR into established voucher programs. These include: Providers, Promotion, Place and Price. These factors have been described in detail in the PCVR Market Development Plan (Chattopadhyay et al, unpublished).

\section{(1) PROVIDERS}

Providers are the various healthcare personnel as well as key stakeholders drawn from the public and private sectors who may be involved in the development and management of the PCVR-VBC program. They include:

- Policy and regulatory bodies (MoH, drug regulatory bodies, national family planning organizations)

- Financial Institutions (to cover the cost of subsidized products and services)

- Voucher management agency

- Independent consulting agencies (to provide technical support)

- Public/private healthcare providers (physicians, nurses, midwives, community health workers (CHWs)

- Community-based and faith-based organizations

- Voucher Distributors (NGOs, individual contractors)

To introduce the PCVR-VBC model, the project (program implementers) will need to collaborate with the Ministry of Health (MoH) and Voucher Management Agency (VMA) to integrate PCVR into their existing $\mathrm{FP} / \mathrm{RH}$ voucher programs. The key goal will be to plan a strategy to incorporate PCVR into their voucher programs as a contraceptive option for PPFP. The initial step will require forming a technical advisory committee (TAC) comprising the key policy and regulatory bodies as well as the donors who fund the voucher program. Once the committee is formed, the PCVR implementing partners will need to work with the regulatory authorities to define the PCVR voucher program policies. These policies may include: the services covered, drug approval and importation, the cost of PCVR to clients, the payment rate to providers and setting the eligibility criteria for clients. It will also be necessary to assess the policies and regulatory framework of ongoing FP/RH voucher programs and tailor and integrate the PCVR-VBC model into the local voucher system.

A stakeholder communication plan may be developed to address programmatic issues raised by the TAC. Key functions and activities of the stakeholder communication plan may include:

- Hosting periodic advisory group meetings to educate the stakeholders on the importance of introducing PCVR for PPFP and to address program issues, such as the design, cost, capacity development and management of quality control.

- Maintaining a stakeholder register to monitor on-going interactions, meetings, challenges, lessons learned and progress made on the program.

- Providing programmatic oversight to the Voucher Service providers (VSPs)

- Reviewing the potential for scale-up to increase access to PCVR in communities with a high unmet need for postpartum family planning. 
The next step will be to work with a contracted Voucher Management Agency (VMA) that will be responsible for integrating the PCVR into the voucher system. The VMA will work closely with the Voucher Service Providers (VSPs) and Community Voucher Distributors (CVDs) and provide key promotional and training materials related to the PCVR. The project will need to organize kick-off meetings and training workshops for the VSPs and CVDs, to orient them on the benefits of using PCVR, frequently asked questions about the vaginal ring and bundling them with postnatal care for maternal voucher users. (Further details on the different tools and training materials are given below.)

In a voucher program, VSPs are responsible for obtaining their own family planning commodities through appropriate supply chains (Arur et al, 2009). The project may need to work with manufacturers and/or distributors providing the vaginal ring to establish a price that VSPs could pay to acquire the PCVR. Likewise, the project will need to work with the VMA to confirm the reimbursable rate to the VSPs that reflects the supplier's PCVR cost plus the provider consultation and related fees.

Similarly, the CVDs play a pivotal role in identifying and educating the clients of RH products and services. The CVDs' primary responsibility is to educate the targeted clients on PCVR and provide them with vouchers to obtain the ring at accredited facilities. In this effort, the role of the CVDs will mainly include: (1) identifying women who have recently delivered, are breastfeeding, and would like to space their next pregnancy; and (2) administer survey questionnaires using a poverty grading tool to determine women's eligibility to receive a voucher for PCVR. All qualifying women who are interested in the vaginal ring may be provided with a voucher to procure the product at the appropriate healthcare centers or outlets.

The PCVR voucher may be sold to consenting clients, which they can redeem at accredited FP/RH health centers or through accredited community health workers, as applicable.

\section{(2) PROMOTION}

The main goal of promotion is to raise awareness and increase the demand for PCVR (in the context of method choice for PPFP) among clients and providers in the targeted countries. Demand for a product is often influenced by socio-economic and socio-cultural factors that determine the uptake of available services (Obare et al, 2012). Effective demand generation will require a targeted marketing strategy and the provision of subsidized products and services to encourage lasting behavior change among the intended clients (Boler and Harris, 2010; Arur et al, 2009).

The key elements for the promotion of the PCVR-VBC model may include:

(1) development and dissemination of information, education and communication (IEC) materials for consumers and providers, (2) mass-media campaign and announcements and (3) capacity building of healthcare providers

Development and dissemination of IEC materials: The implementing partners will need to use a sustained marketing strategy to facilitate the demand for PCVR. In this effort, educational tools, communication strategies and the voucher design will need to be developed for the target consumers and providers in consultation with public opinion leaders and key stakeholders. Additionally, to facilitate easier recognition and familiarity of the new vouchers, it is recommended that PCVR marketing 
materials (such as posters, banners, leaflets, palm cards, brochures) and vouchers be designed to conform to the local format and language of ongoing voucher programs.

As part of the dissemination strategy, the PCVR promotional materials may be distributed through a network of accredited providers and local community-based distributors. These materials may be disseminated through community meetings, events, door-to-door home visits and at healthcare facilities providing safe motherhood and postpartum family planning services. Additionally, the marketing and promotional materials can also be made available through various advocacy groups, community-based organizations, faith-based organizations, pharmacies, and social marketing organizations located within the targeted geographic areas.

Mass media campaigns: Campaigns to launch PCVR may be carried out based on marketing budgets and concessions with the Ministry of Health and key stakeholders. For example, a local advertising agency may be hired to promote and increase awareness of PCVR through radio public service announcements (PSAs), advertising through public transportation systems (putting up posters in buses and trains) and other mainstream media channels such as local newspapers, television, internet and social media. In addition, PCVR will be promoted through relevant media outlets used by the ongoing voucher programs.

Capacity Building of Providers: The goal of the project will be to train CVDs and VSPs on strategies to promote PCVR among eligible clients in the community and ensure that targeted clients have a good understanding of the use and benefits of PCVR. In this effort, the project may need to develop a provider training package for PCVR-VBC that is tailored to the local context of service delivery. This may include training modules on quality assurance benchmarks for PCVR delivery; counseling and role-play modules to educate postpartum women on family planning, breastfeeding/ lactational ammenorrhea method (LAM) method and the benefits of using PCVR; and the dissemination of IEC materials. It will be necessary to ensure that target beneficiaries are informed about the benefits of using family planning products, and any myths and misconceptions related to postpartum family planning will need to be dispelled before they can be convinced to use the FP vouchers.

\section{(3) PRICE}

One of the key factors that prevent women in low-income communities from obtaining services for family planning from the providers is the price of the contraceptive. The pricing strategy of the products will play an important role in the successful implementation of the PCVR-VBC model, and it will need to be addressed in detail. Country-specific pricing guidelines regulated by the $\mathrm{MoH}$ as well as government and donor funding for family planning will need to be assessed prior to implementation.

In general, decisions about the prices at which PCVR will be provided to target clients will depend on several factors including: manufacturing cost of the product; the volume of procurement and distribution of product; source of distribution and delivery channels and infrastructure and staffing costs. The goal of the PCVR-VBC will be to negotiate a subsidized pricing strategy with the $\mathrm{MoH}$ and financial institutions for low-income target clients.

The PCVR-VBC model will consist of three primary cost components:

- Consumer price: The subsidized price of PCVR to the target population

- Provider price: The reimbursement of the price of the PCVR service package

- Program Management Cost: The administrative, procurement and distribution costs of setting up and running the VBC program 
The product's initial price may be estimated based on the price at which public and private providers (including healthcare professionals and procurers) are willing to sell the ring. An appropriate price point and level of subsidy required for the continued demand and availability of PCVR in the country will need to be determined. One possibility is to conduct a willingness-to-pay (WTP) study with consumers and providers. Additionally, competitive pricing may be negotiated based on the price range of comparable contraceptives available to postpartum women. For example, given that a single PCVR is effective for 3 months, its price may be pegged to the cost of three cycles of Progestin-only Pills (PoPs). Moreover, unlike other contraceptives such as intrauterine contraceptive devices (IUCDs) or an implant, PCVR does not require any medical procedures (MDP, 2014). Thus it is expected that PCVR can be priced competitively since it requires only basic counseling services on how to correctly insert and remove the ring, how to address potential isues during use, e.g. expulsion, and where and when to go for resupply.

To negotiate a competitive and sustainable pricing strategy for PCVR, the project may need to arrange meetings between the VMA, donor(s), governing bodies and supply-chain managers to review the WTP profile of the target population, the potential volume of procurement of the product as well as the estimated size of the targeted market.

The project will also need to collaborate with existing donors who provide funding for FP/RH products and services to introduce and integrate PCVR into their voucher system. It is recommended that a fixed provider price be set for PCVR, as compared to a provider-specific fee-for-service model, to avoid complications in reimbursements made to VSPs. Efforts will also be made to identify local and international donors to supplement the cost of the vaginal ring, including funding support from the Ministry of Health. It is expected that as the demand for PCVR increases, the service delivery cost and reimbursement rates to providers will be reduced further, making it more cost effective for those who may not be able to afford to provide or use the product at the outset.

Lastly, a budget plan may need to be created for the initial administrative costs during the early stages of implementation. This will include the cost to set up meetings with providers to introduce the benefits of PCVR. In addition, the cost to develop training modules for PCVR integration will need to be factored in. These costs will include training on claims systems, monitoring, development of training modules on PCVR integration into the program, and dissemination strategies and media campaigns to educate the public.

Table 2 outlines key administrative and program management costs for the PCVR-VBC model. These include some of the initial setup costs as well as ongoing costs to integrate and scale-up PCVR within an existing voucher program.

TABLE 2: ADMINISTRATIVE AND PROGRAM MANAGEMENT COST FOR THE PCVR-VBC MODEL

\begin{tabular}{|l|l|}
\hline Setup costs to introduce PCVR-VBC & Ongoing Costs for PCVR-VBC \\
\hline - Pre-launch planning with VMA, Donors and MoH - to review and adapt & - Program management \\
to on-going voucher system & - Continued training of providers \\
- High-level advisory group meetings to launch PCVR & - Paying distributors \\
- Develop training materials for VSPs and CVDs & - Service provision cost \\
- Capacity building of accredited providers and contracted distributors & - Data entry to maintain claims \\
- External technical and programmatic support & - Monitoring and evaluation \\
- Kick-off marketing/advertising campaign for PCVR & - Continued marketing \\
- Identify donors and procurers for PCVR & - Scale-up plans \\
- Establish monitoring and evaluation plan & - Community verification of clients \\
- Community Verification of Clients & \\
\hline
\end{tabular}

Adapted from: Vouchers for Reproductive Healthcare services in Kenya and Uganda, Bellows N., 2012 
As listed in the table, the administrative costs at the introductory stage of the PCVR-VBC model may have various associated costs to strategically identify and introduce the vaginal ring to the key stakeholders. The cost of training and advocacy materials that will need to be designed relevant to the local context is another significant cost to set up the program. Additionally, external consultants to help with technical and programmatic support during the initial phase may be hired based on funding availability.

In summary a majority of the cost for a multi-year initiative (for PCVR-VBC) will likely be associated with the reimbursement cost to the providers (Bellows N., 2012). The initial setup cost to launch and integrate PCVR will be a high percentage at first, but eventually the administrative cost of the PCVR voucher system is expected to be reduced over time, given that the demand of PCVR increases and the program is monitored efficiently.

\section{(4) PLACE}

Place represents all of the locations at which PCVR will be available at subsidized rates and the geographic zones where there is a high unmet need for postpartum family planning. The goal of the PCVR-VBC model is to make the contraceptive vaginal ring available through both public and private healthcare facilities and channels to low-income clients residing in peri-urban/slum or rural communities.

As a strategy to reach targeted clients, an effective logistics management system may be developed for PCVR using a "Client \& Provider Centric Approach" to map the country-specific supply-chain mechanisms and to identify places where women are most likely to access family planning services and contraceptives within the public and private sectors (Chattopadhyay et al, unpublished).

As a starting point, the project may identify the districts where the voucher system is currently operational and then with the support from the VMA and $\mathrm{MoH}$ map the locations where accredited healthcare providers offer other FP/RH products and services. During the introductory phase, the project may invest in locations or districts where there may be a higher interest among the providers to introduce the ring. A survey may be carried out to map the providers who might be interested in providing the ring at their clinics or community-based outlets. This survey may be helpful in evaluating the potential demand and supply-chain mechanism in the respective community. Furthermore, based on the information collected during the pilot phase, the project may modify its marketing strategy in order to reach additional accredited providers and contracted distributors to provide PCVR.

The project will also need to coordinate with the VMA and the MoH to ensure a PCVR supply chain is in place to avoid stock-outs. For example, the market demand may be identified by the service providers and distributors, who in turn will need to contact the VMA to initiate the procurement process with manufacturers (bidding, pricing and distribution). The manufacturer, based upon the order and timeframes, will ship the products to the related distribution channels on a timely basis. Furthermore, to monitor the efficacy of this process, effective checks and balances will need to be incorporated through an order entry system. The VSPs can replenish their stocks according to the number of vouchers used and the receipt of monthly payments.

PCVR vouchers may be sold to clients who wish to use the vaginal contraceptive method for family planning.Clients will be able to redeem them at accredited FP/RH health centers or through accredited 
community health workers, as applicable. Given the ease of use of the vaginal ring and the non-clinical nature of its insertion and removal (eliminating the need for a skilled health provider's involvement), alternate arrangements can be explored with the governing bodies to provide PCVR directly through home-visits made by $\mathrm{CHWs}$. This strategy will reduce the need for the client to travel to healthcare facilities and will avoid further transportation and service cost. For example, CHWs may provide FP vouchers as well as the product of choice including the PCVR (at the same time) to clients who wish to obtain family planning products and services.

It is expected that postpartum mothers who choose to use the PCVR will require between 2-4 rings in the first year following childbirth. It may be important to train the VSPs and CVDs to refer the CHWs to clients who are using this method and prefer not to come to a healthcare facility and/or are lost to follow-up. Depending on the voucher program policies, the clients may also be given the option to obtain the PCVR through contracted social franchising outlets or facilities participating in the voucher program. Besides the eligibility assessment of the poverty grading tool, clients will need to be from the same targeted district as the provider in order to obtain the PCVR voucher. Clients who visit from other districts will need to be directed to other health providers who offer the vaginal ring and may have to obtain it at full price.

A backup plan for challenges such as staff turnover and delays in reimbursement and stock-outs will need to be managed as part of the logistics strategy for the program. Another common issue in the voucher system is the management of fraud. To deal with this issue, the project and the VMA will need to plan effective methods to reduce voucher frauds, service provisions frauds, claims processing fraud, siphoning of funds by falsifying the number of claims (USAID, 2009). Best practice methods to control fraud that are already in place may be adopted. For example, bar codes or unique IDs may be used on vouchers to control fraud during the distribution of vouchers. Strict guidelines and policies may be developed for the providers and distributors to follow and prevent fraud. For example: any dishonest providers and distributors will be excluded from the system. Lastly, the project will need to ensure that payments to providers are made promptly, based on the pre-defined terms for the reimbursement for service delivery. These prompt payments may reduce the financial temptation to commit fraud (Arur et al, 2009).

Studies have shown that one of the challenges of scale-up is reaching low-income individuals in remote regions (Arur et al, 2009). These individuals have little or no access to transportation. A possible solution may consist of providing subsidized vouchers for transportation depending on the geographical distribution of the providers and target clients. Moreover, since PCVR does not require a medical procedure, a mid-level provider or community-based distributor may provide additional contraceptive rings (dependent on the established network of providers, supply chain manager and supplementary incountry programs (such as social franchising, FP/immunization) and government policies. 


\section{Implementation of the Model in Three Phases}

The following section presents a timeline for the implementation plan. It is proposed that the implementation of the PCVR-VBC model will be carried out in 3 phases:

- $\quad$ Phase 1: Design Phase

- $\quad$ Phase 2: Start-up Phase

- $\quad$ Phase 3: Scale-up Phase

Each phase will review the three key components: duration, quantity of rings, and the study site. Also each phase will need to be described in detail, providing key recommendations for transitioning to the next phase and cohesively implementing the program.

\section{Phase 1: Design Phase}

The key goal of the design phase is to pilot test the PCVR-VBC model to evaluate the process and program functions. Based on the findings of the pilot test, modifications may be made to improve the program.

Duration: 2 years

- 6 months - pre-implementation planning

- 1 year - program implementation (pilot test in select sites)

- 6 months - program evaluation and modification to model design

Quantity of rings: 400

Study sites: 2-4 public and 2-4 private healthcare facilities

As part of the initial design testing phase, the PCVR-VBC model will be pilot-tested in one district. From 4 to 8 study sites or accredited voucher-based healthcare facilities may be selected to implement the model. This model will be delivered through an equal number of public and private healthcare facilities to test the system across the total market. Essentially, 2 private-sector and 2 public-sector healthcare facilities can be selected to test the model. Up to 400 vouchers can be redeemed during the 1 year of actual program implementation. Given that every interested postpartum woman uses at least 2-4 vaginal rings in the first year following childbirth, the goal during this phase will be to reach between 100-200 women.

Depending on the in-country costing plan, women may cover one-third of the total cost of the vaginal ring. For example, if a single PCVR costs $\$ 3$ (including manufacturing, management and procurement costs), then qualifying women may buy a PCVR voucher at $\$ 1$ (one-third the actual price of the PCVR) to obtain the vaginal ring at a subsidized cost.

Initial planning and administrative/programmatic costs will vary by country. Key personnel may be identified and trained for the initial pilot testing phase and to manage administrative and programmatic issues related to implementation. Furthermore, evaluations may be carried out through interviewing providers and surveys of participants who use the voucher system. 


\section{Phase 2: Start-up phase}

During the second phase, the key goals of the PCVR-VBC model will be to integrate PCVR as a contraceptive option into existing FP/RH voucher programs. The PCVR-VBC model will be implemented within all districts where there is sufficient interest and the voucher program is currently operational.

\section{Duration: 2.5years}

- 6 months - pre-implementation planning

- 1.5 years - program implementation across districts

- 6 months - evaluation and reporting

Quantity of rings: forecasted number based on the geography and size of the target population

Study sites: introduce at healthcare facilities across the districts where voucher programs are currently operational

\section{Phase 3: Scale-up Phase}

The goal of the scale-up phase is to expand the voucher program to new locations where there is a high unmet need for PPFP services. Secondly, depending on the success of the PCVR-VBC program, strategic communication and negotiations will be conducted with the government to incorporate the model as part of their national action plan. The success of the program may dictate how the program may be expanded to the other areas. An overall strategy will be to look for related funding opportunities and to negotiate with the Ministry of Health the integration of this program with other national action plans.

Duration: 2 years

- 3 months - pre-implementation planning

- 1.5 years - program implementation within existing and new districts as well as coordination with the $\mathrm{MoH}$ to integrate the program into regional and national action plans

- 3 months - evaluation and development of a policy guideline to integrate PCVR-VBC into the national action plan

Quantity of rings: forecasted number based on the geography and size of the target population

Study sites: introduce at healthcare facilities in new districts as the fourth factor 


\section{Conclusion}

In summary, it will be necessary for the program implementers (project) to involve the governing bodies and donors from the outset in the design and management of the PCVR-VBC model. Doing so will help build their knowledge and understanding of the importance of PCVR and will also increase the chances of gaining their support in the development of sustainable approaches (Grainger, 2014). Investments in research and development of both providers and clients will need to be made on their PPFP-related knowledge, service use patterns, perceived needs, barriers and willingness-to-pay when designing voucher benefits. It will also be necessary to design appropriate marketing and behavior communication change materials for demand generation and the effective delivery of services for PCVR. The project will need to identify the key functions for an effective voucher system and ensure that there is key support from the larger health system and the voucher management agency. Depending on the level of interest and support from key stakeholders, additional technical experts and consultants may need to be hired to kick-start and run the voucher program.

A strategy that may need to be explored is to determine how to integrate or package PCVR vouchers with other high-demand vouchers and offer them at a discount. For example, the popularity of the Safe Motherhood (SM) Voucher in Kenya indicates that postpartum family planning could present a logical cross-over to PPFP, with a "Safe Motherhood Plus" voucher that subsidizes both SM and PCVR services (Arur et al, 2009).

Larger health system constraints to quality service delivery will need to be regularly monitored and addressed. For example, systemic issues such as stock-outs or the unwillingness of VSPs to invest in PPFP products becaue of the low volume of FP clients will need to be addressed. The project will need to assess such systemic problems and design solutions in the initial start-up phase. Additionally, if PPFP is free at public facilities, then the fact that voucher clients have to pay a subsidized rate for FP products may pose challenges in the demand and scale-up of PCVR. Also, regulatory and distribution decisions on making PCVR available over the counter will need to be explored, and effective strategies to distribute the vaginal ring through pharmacies and drug stores will need to be incorporated.

To gradually increase the provider base across the region, the project may consult the VMA and the $\mathrm{MoH}$ to identify and map new providers who qualify for this program. For example, distribution strategies through CHWs may be established with the local government. CHWs may be trained to provide PCVR directly to consumers through home-visits. This strategy may help reduce additional service delivery and transportation costs as well as help maintain confidentiality.

To ensure the future scale-up of voucher programs, local governments will need to prioritize and integrate voucher as part of their national financing policies. Further government should provide adequate funding, play a stewardship role and seek opportunities to utilize existing platforms to scale up such strategies (Abuya et al, 2012). 


\section{References}

Abuya, T., Njuki, R., Warren, E., Okal, J, Obare, F., Kanya, L., Askew, I. and Bellows, B. (2012). A Policy Analysis of the implementation of a Reproductive Health Vouchers Program in Kenya. BMC Publc Health 2012, 12:540 doi: 10.1186/1471-2458-12-540

Arur, A, Gitonga, N., O'Hanlon, B., Kundu, F., Senkaali, M. and Ssemujju, R. (2009). Insights from Innovations: Lessons from Designing and Implementing Family Planning/Reproductive Health Voucher Programs in Kenya and Uganda. Bethesda, MD: Private Sector Partnerships-One project, Abt Associates

Boler T and Harris, L. 2010). Reproductive Health Vouchers: from Promise to Practice. London: Marie Stopes International

Bellows, BW et al. (2013). ATaxonomy and Results from a Comprehensive Review of 28 Maternal Health Voucher Programmes. Journal of Health Popl Nutr 2013 Dec; 31(4) Suppl 2:S106-S128

Bellows, B. (2012). Results-based financing and family planning: Evidence from reproductive health vouchers programs. Population Council [Power Point Presentation]

Bellows, N. (2012). Vouchers for Reproductive healthcare services in Kenya and Uganda [Discussion paper]. Nairobi : Population Council

Boler T and Harris, L. (2010). Reproductive Health Vouchers: from Promise to Practice". London: Marie Stopes International

Chattopadhyay I. and Townsend J. (unpublished). Market Development Plan: To launch PCVR and NES/EE CVR in low-income countries in sub-Saharan Africa \& Asia. Washington D.C.: Population Council

Grainger, C., Gorter, A., Okal, J. and Bellows, B. (2014). Lessons from sexual and reproductive health voucher program design and function: a comprehensive review. International Journal for Equity in Health 2014, 13:33

Kanya, L., Obare, F., Warren, C., Abuya, T., Askew, I. and Bellows, B. (2014). Safe motherhood voucher programme coverage of health facility deliveries among poor women in South-western Uganda. Washington D.C.: Population Council

Morgan, L. (2011).More Choices for women: Vouchers for Reproductive Health in Kenya and Uganda. Washington D.C.: The World Bank

Obare, F., Wilson, L., Birungi, H., Eseoise Itombra, E. Clark, H. and Ramarao S. (2012). Progesterone vaginal ring country mapping: Kenya. New York: Population Council.

Options Consultancy Ltd. (2014). A Quick Guide to Developing Voucher Programmes. Retrieved from www.rhvouchers.org

Ross J. and Winfrey W. (2001) Contraceptive Use, Intention to Use and Unmet Need during the Extended Postpartum Period. International Family Planning Perspectives, Vol. 27, Number 1, New York: Guttmacher Institute.

Warren C., Abuya T., Obare, F., Sunday, J., Askew, I. and Bellows, B. (2011). Evaluation of the impact of the voucher and accreditation approach on improving reproductive health behaviors and status in Kenya. BMC Public Health 2011, 11:177

WHO and UNICEF. (2014). Countdown to 2015- Fulfilling the Health Agenda for Women and Children: The 2014 Report. Retrieved from http://www.countdown2015mnch.org/documents/2014Report/Part 2(14-25).pdf

Van de Poe. E, Flores G., Ir.P, O'Donnell O.and Van Doorslaer E. (2014).Can vouchers deliver? An evaluation of subsidies for maternal health care in Cambodia. Bulletin of the World Health Organization 2014; 92:331-339. Doi: http://dx.doi.org/10.2471/BLT.13.129122 


\section{Appendices}

\section{APPENDIX 1}

\section{AN ILLUSTRATIVE EXAMPLE OF A SUCCESSFUL VOUCHER SYSTEM (THE KENYA RH-OBA PROGRAM)}

\section{Case Study: The Kenya Reproductive Health Output Based Aid (RH-OBA) program}

An example of the implementation of the PCVR-VBC model could be to integrate it into an ongoing an established FP/RH voucher program, such the Reproductive Health Output Based Aid (RH-OBA) program currently operational in Kenya.

The following case study highlights the key programmatic and operational functions of a successful voucher program.

The Kenyan Ministry of Health (MoH) with support from the German Development Bank (KfW) has implemented a Reproductive Health Output-Based Aid (RH-OBA) voucher program since 2006. A key goal of the RH-OBA was to increase access to safe motherhood and family planning services (Bellows et al, 2013). The program beneficiaries use vouchers to access highquality antenatal, delivery, postnatal care, infant care and family planning services through accredited providers (Abuya et al, 201; Warren et al, 2011; OBA website, 2014; Bellows et al, 2013).

The RH-OBA program in Kenya currently offers vouchers for family planning services at subsidized rates at public and private providers in six counties. The $\mathrm{RH}-\mathrm{OBA}$ program has a fairly established large-scale voucher program with a strong support from the Kenyan Ministry of Health (Arur et al, 2009). The program has seen a steady increase in sales of RH-OBA vouchers - and the revenue generated has allowed for providers to improve the quality of services, better staffing as well as infrastructural improvements to their health facilities (Bellows N, 2012).

Following the success of the RH-OBA voucher system, the Government of Kenya has adopted this output-based financing mechanism into their "Vision 2030" national action plan. The Kenyan Ministry of Health $(\mathrm{MoH})$ prioritizes family planning and LARCs as a top national health priority and strongly advocates for public-private partnerships for health service delivery. This methodology aligns with the goals and objectives of the PCVR-VBC model. 


\section{APPENDIX 2}

\section{OVERVIEW OF THE KENYA RH-OBA SYSTEM}

The sections below highlight a brief overview and desgin funcitions of the RH-OBA Program

\begin{tabular}{|c|c|}
\hline Program Details & KENYA MODEL \\
\hline Name of the Program & Output-Based Aid (OBA) or the Reproductive Health OBA (RH-OBA) \\
\hline Key Goals and Objectives & $\begin{array}{l}\text { The overarching goal of the OBA program is to improve access to RH } \\
\text { services, decrease maternal and child deaths and increase acceptance of } \\
\text { the long term family planning services }\end{array}$ \\
\hline Funding organization(s) & $\begin{array}{l}\text { RH-OBA was established in 2005, with funding from the Government of } \\
\text { Kenya (GoK) and the German Development Bank (KfW). KfW has funded } \\
\text { Euro } 8.4 \text { million in Phase1 ( } 2005-08) \text {, Euro } 13 \text { million for Phase } 2 \text { (2008- } \\
\text { 11), Phase } 3(2012-15)-3 \text { districts will be added, FP services will } \\
\text { integrate short-term methods. ( } 21 \% \text { of the budget was spent on } \\
\text { management, training and marketing in Phase } 1)\end{array}$ \\
\hline Voucher Services offered & $\begin{array}{l}\text { 1) Safe motherhood: antenatal care, facility-based deliveries and post- } \\
\text { natal care } \\
\text { 2) Modern methods of long-term family planning } \\
\text { 3) Gender-based violence recovery }\end{array}$ \\
\hline Family Planning services & $\begin{array}{l}\text { FP services as intrauterine contraceptive devices (IUD) and both male } \\
\text { (vasectomy) and female (bilateral tubal ligation) voluntary contraceptive } \\
\text { surgery are provided. The vouchers costs Ksh100 ( \$1) and buys up to } \\
\text { Ksh 3,000 worth of services }\end{array}$ \\
\hline Free or Subsidized & Subsidized \\
\hline Location & $\begin{array}{l}\text { OBA is currently operational in } 4 \text { rural districts (Kilifi, Kitui, Kiambu and } \\
\text { Kisumu) and } 2 \text { slum communities (Korogocho and Viswandani) in Nairobi. } \\
\text { Expansion to 3-4 additional counties is slated for } 2015\end{array}$ \\
\hline \multicolumn{2}{|l|}{ Management Stakeholders } \\
\hline $\begin{array}{l}\text { Voucher Management } \\
\text { Agency }\end{array}$ & $\begin{array}{l}\text { PriceWaterhouseCoopers (PWC), a private for-profit firm is responsible for } \\
\text { managing the daily operations on the program. It plays a key role in } \\
\text { managing claims of VSPs, identifying CVDs and monitoring fraud. }\end{array}$ \\
\hline $\begin{array}{l}\text { Key Stakeholders/ } \\
\text { Managing Partners }\end{array}$ & $\begin{array}{l}\text { Kenya Ministry of Health (formerly two ministries: Ministry of Public Health } \\
\text { and Sanitation/ Ministry of Medical Services) } \\
\text { National Coordinating Agency for Population and Development NCAPD } \\
\text { (2006-2011, project management) } \\
\text { Ministry of Health (project management, since 2011) }\end{array}$ \\
\hline Accreditation Process & $\begin{array}{l}\text { The acceditaation process was developed by Population Council and } \\
\text { Department of Reproductive Health and was executed by the National } \\
\text { Hospital Insurance Fund }\end{array}$ \\
\hline \multicolumn{2}{|c|}{ Service Delivery and Demand Generation } \\
\hline $\begin{array}{l}\text { Voucher Service Providers } \\
\text {-VSPs }\end{array}$ & $\begin{array}{l}\text { The RH-OBA health service providers or VSPs comprise of a network of } \\
\text { more than } 250 \text { accredited public and private health facilities providing FP } \\
\text { and safe motherhood (SM) services. The VSPs are reimbursed for their } \\
\text { services, on submitting correctly filled claims, the service provided is } \\
\text { within the scope of the contract, and no fraud or irregularities are detected } \\
\text { (Bellows, N.2012) }\end{array}$ \\
\hline $\begin{array}{l}\text { Community Based } \\
\text { Distributors - CVDs }\end{array}$ & $\begin{array}{l}\text { The CVDs are identified and retained by PwC. The CVDs are trained to } \\
\text { screen potential clients using a poverty-grading tool. PwC pay the }\end{array}$ \\
\hline
\end{tabular}




\begin{tabular}{|c|c|}
\hline & $\begin{array}{l}\text { contracted CVDs a salary retainer. The CVDs are contracted for short-term } \\
\text { (three-month) terms, and their contracts are renewed only if PwC deems } \\
\text { the number of voucher sales to eligible poor clients to be satisfactory }\end{array}$ \\
\hline Marketing strategy & $\begin{array}{l}\text { In } 2006 \text {, Lowe Scanad, an advertising agency implemented a one-month } \\
\text { launch campaign to increase awareness of FP and SM vouchers at each } \\
\text { project site. The launch campaign used multiple media including radio } \\
\text { spots, road shows, community events and road shows. It also distributed } \\
\text { materials such as posters, brochures, banners and t-shirts. Ongoing } \\
\text { demand generation is maintained through mass media and community } \\
\text { meetings }\end{array}$ \\
\hline Poverty Grading Criteria & $\begin{array}{l}\text { A poverty grading tool is used to select poor women eligble for vouchers. } \\
\text { This tool however may be tailored to fit the differing poverty assessment } \\
\text { criterias between the targeted districts (Bellows, N.2012) }\end{array}$ \\
\hline \multicolumn{2}{|l|}{ Cost of Vouchers } \\
\hline Cost of the Voucher & $\begin{array}{l}\text { Safe motherhood: } 200 \text { Kenyan Shillings USD } \$ 2.70 \\
\text { Family planning: } 100 \text { Kenyan Shillings } \sim \$ 1.35 \\
\text { (Bellows N.,2012) }\end{array}$ \\
\hline Voucher price to client & USD \$1.50 (Bellows et al , 2013) \\
\hline $\begin{array}{l}\text { Voucher claims and } \\
\text { reimbursement rates } \\
\text { (average) }\end{array}$ & $\begin{array}{l}\text { VSPS submit claims once a month to PWC for processing. } \\
\text { Reimbursement rates: } \\
\text { USD } \$ 13 \text { for prenatal care \& USD } \$ 66 \text { for normal delivery } \\
\text { USD } \$ 276 \text { for complicated delivery (includes caesarean) } \\
\text { USD } \$ 13 \text { - } \$ 39 \text { for family planning, depending on method }\end{array}$ \\
\hline \multicolumn{2}{|l|}{ Long-term Sustainability plan } \\
\hline $\begin{array}{l}\text { Scale-up /Long-term } \\
\text { sustainability plans }\end{array}$ & $\begin{array}{l}\text { The Government of Kenya is responsible for financing and implementing } \\
\text { the program, with support from development partners. RH-OBA program } \\
\text { has been earmarked for scale-up under the vision } 2030 \text { development } \\
\text { blueprint }\end{array}$ \\
\hline \multicolumn{2}{|c|}{ Key Design Features of the RH-OBA Program ${ }^{1}$} \\
\hline Key Features & Characteristics \\
\hline $\begin{array}{l}\text { Selection and Accreditation } \\
\text { Process }\end{array}$ & $\begin{array}{l}\text { - Mapping of facilities in selected districts are identified based on the } \\
\text { level of care and FP/RH service provided } \\
\text { - Facilities with basic infrastructure, equipment and staffing are } \\
\text { necessary to meet the selection criteria } \\
\text { - Selection of VSP and CVDs made based on set criteria, adapted from } \\
\text { - existing national standards } \\
\text { - Contractual agreements with selected VSPs and distributors }\end{array}$ \\
\hline Marketing and Distribution & $\begin{array}{l}\text { - Marketing: designed to use local media, radio shows, vans buses, } \\
\text { fliers and posters and marketed as VOCHA brand } \\
\text { - Distribution: direct distribution where vouchers are sold to clients in } \\
\text { their homes; use of specific locations where clients will go to specific } \\
\text { points to access the vouchers such as pharmacies. }\end{array}$ \\
\hline $\begin{array}{l}\text { Claims and reimbursement } \\
\text { process }\end{array}$ & $\begin{array}{l}\text { - Monthly reimbursements to providers based on submission of claims } \\
\text { - Reimbursement fee set based on a market analysis of what different } \\
\text { facilities charged and negotiated }\end{array}$ \\
\hline
\end{tabular}

1 Arur et al, 2009 


\section{APPENDIX 3}

\section{SYNOPSIS OF THE PCVR -VOUCHER BASED CARE (PCVR-VBC) MODEL}

The PCVR-VBC Model is a mechanism to provide PCVR to qualifying low-income clients at subsidized rates.

PCVR vouchers can be purchased through contracted voucher distributors. Clients can then exchange the voucher for the PCVR through the contracted voucher service providers.

The key strategies for implementation of the PCVR-VBC model have been described utilizing the 4 P's of Marketing:

\section{Providers}

- 5 primary actors of a voucher system: Financing organization, Ministry of Health (MoH), Voucher

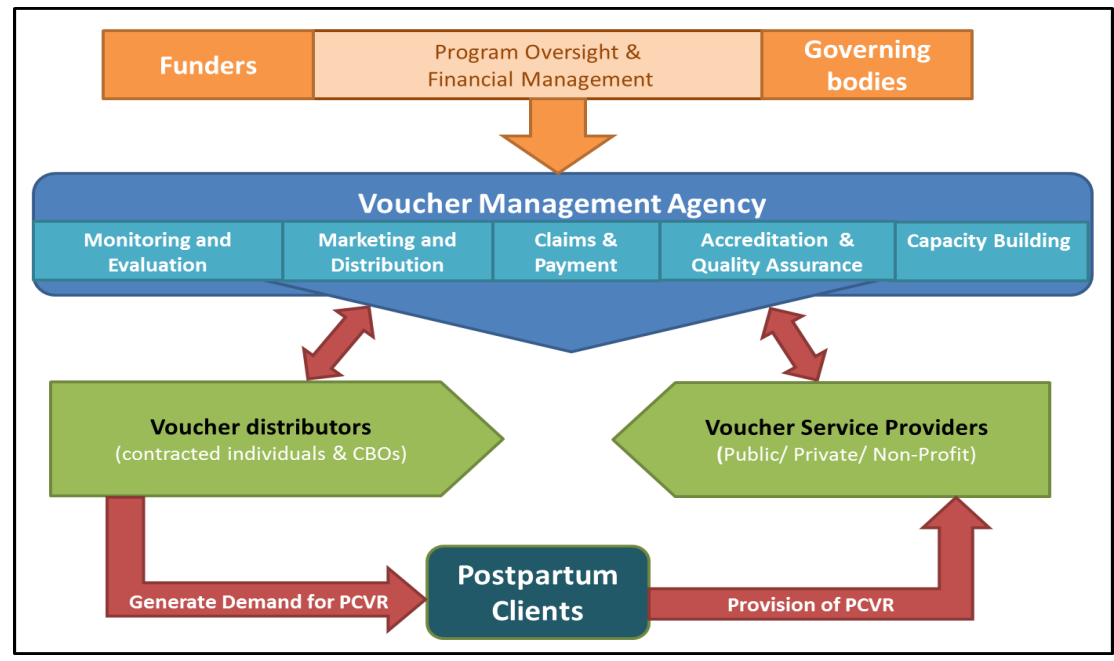
Management Agency (VMA), Voucher Service Providers (VSPs) and Community Voucher Distributors (CVDs)

- Collaborate with $\mathrm{MoH}$ and VMA to integrate PCVR into their existing FP/RH and maternal health voucher system

- Organize kick-off meetings and training on PCVR along with the VMA for the contracted VSPs and CVDs

- Ensure VSPs receive regular PCVR stocks through appropriate supply chains

- Manage CVDs role in identifying, educating and distributing PCVR vouchers to targeted clients

\section{Place}

- Identify districts and interested VSPs where the FP/RH voucher programs are currently operational

- Coordinate with the local VMA and MoH to ensure supplies for PCVR to the accredited VSPS

- Provide options for the PCVR to be available through CHWs, social marketing organizations and pharmacies

\section{Promotion}

- Collaborate with the VMA and MoH to design vouchers and IEC materials similar to the local format

- Integrate PCVR training materials with existing job-aids and tools based on the local context

- Develop a strategy to distribute PCVR promotional materials through CVDs, VSPs and key stakeholders

- Plan for mass media marketing through radio, local newspapers, television, internet and social media

\section{Price}

- Determine the manufacturing cost, volume of procurement and client willingness to pay in target area

- Identify local and international funding sources to provide subsidies for PCVR

- Negotiate a competitive and sustainable pricing for PCVR with donors, governing bodies and VMA

- Determine fixed provider price for PCVR, for reimbursements made to VSPS

- Factor in initial setup cost and ongoing cost to integrate PCVR-VBC into existing voucher programs

The key stages of implementation of the PCVR-VBC intervention (3 phases):

$\checkmark$ Design phase: Pilot test the model in one district or county

$\checkmark$ Start-up Phase: Integrate PCVR as a contraceptive option into existing RH/FP programs

$\checkmark$ Scale-up Phase: Introduce the PCVR-VBC model to new locations where there is an unmet need for PPFP 



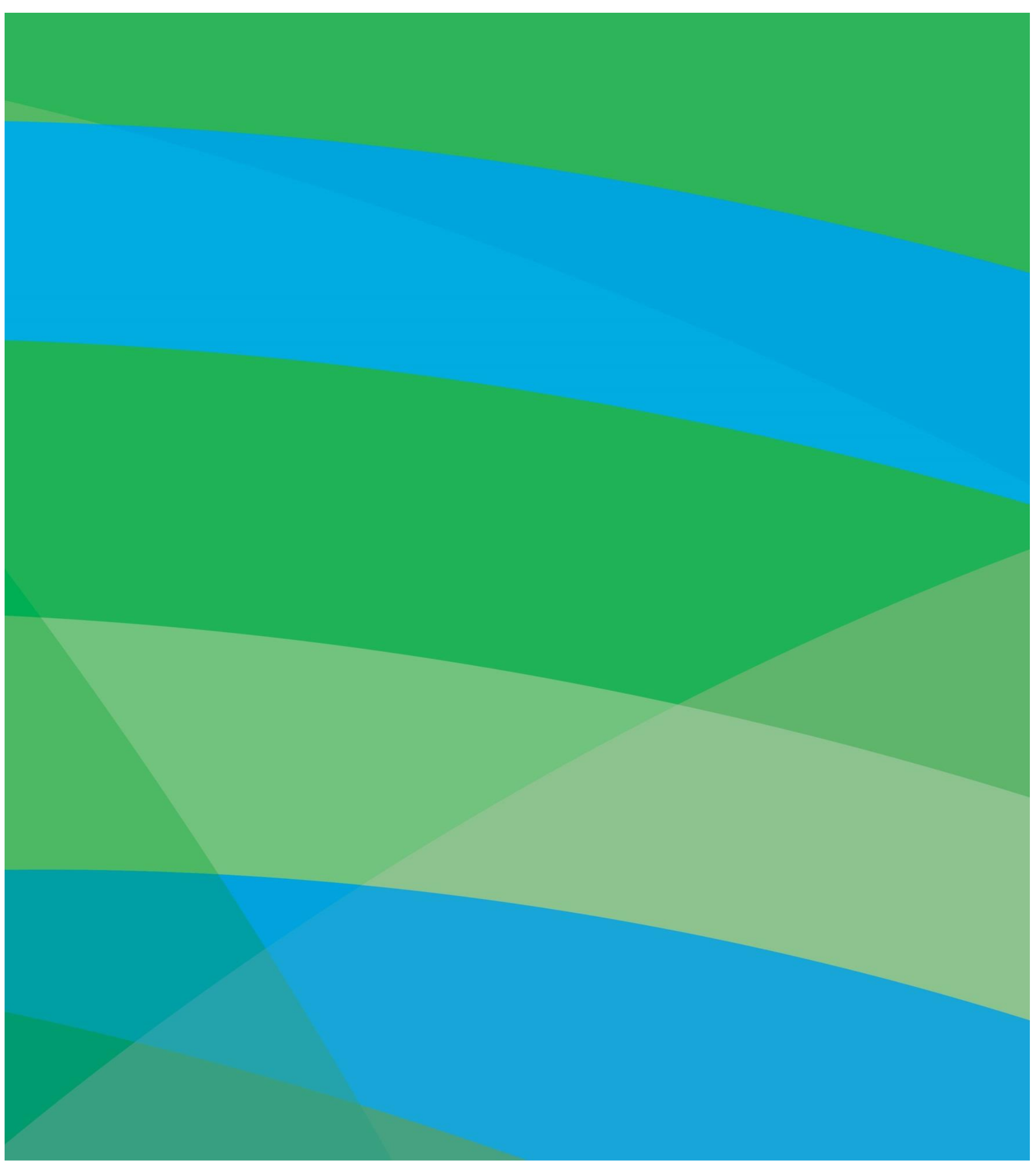

POPULATION COUNCIL

Ideas. Evidence. Impact.
Population Council 4301 Connecticut Avenue NW Washington DC 20008, USA

popcouncil.org 